\title{
A COMPARATIVE EVALUATION OF THE BEHAVIOUR OF SOME TYPICAL FLOATING OFFSHORE STRUCTURES
}

\author{
Liviu Crudu \\ "Dunarea de Jos" University of Galați, \\ Faculty of Naval Architecture \\ 47, Domneasca Street, 800008, România \\ E-mail: liviu.crudu@ugal.ro
}

\author{
Oana Marcu \\ Progressive Ship Design, \\ 10, Lupeni Street, 900720, \\ Constanța, România \\ E-mail: progressiveshipdesign@gmail.com
}

\section{Diana Donose}

Damen Shipyards Galați,

132, Al. Moruzzi Street, 800223, România

e-mail: diana.donose@damen.com

\begin{abstract}
It is commonly accepted that, during the design process, the characteristics of the location play a major influence leading to the design wave principle. In fact, as compared to ship design process, in case of offshore structures including the ship shaped ones, conceptual design plays a decisive role regarding the capability to safely operate at zero speed on locations in order to reach a high operational index in rough seas. This is directly linked to the limits of the accelerations due to body behaviour in waves which are clearly stated related to the comfort on board corresponding to different types of activities (intellectual work, manual work etc.). On the other hand, the above mentioned restrictions and the operational limits related to the body motions amplitudes, need to be considered. Consequently, the body geometry as well as the masses distribution solutions is mandatory to be carefully evaluated taking also into account the direct influences on the induced structural loads. To this purpose, a comparative evaluation of the Response Amplitude Operators (RAO's) has been performed for six different bodies consisting in an AHTS ship, a floating crane, a semisubmersible and a group of three pipe laying vessels. The results presented in the paper could be useful when future development of activities on a certain location is envisaged providing quantitative data as well as qualitative ones, giving reliable information depending on the geometry and mass distribution.
\end{abstract}

Keywords: structural loads, Response Amplitude Operators, mass distribution.

\section{INTRODUCTION}

The most important stage during the design process of an offshore structure is the conceptual one followed by FEED (Front End Engineering Design).

The complexity of the analyses is dictated by the characteristics of the location in conjunction with the operation to be performed on a given location. In order to comply with owner's requests an important vol- ume of investigations has to be spent to evaluate the floating body dynamics which is strongly dependent on body geometry and inertial characteristics, i.e. masses distribution on board. Once this first step is initially completed, the evaluation of the Response Amplitude Operators (RAO's) becomes mandatory as far as they are responsible of the accelerations and induced structural loads depending on the waves, current and wind on the specified location [4]. 
The analysis is performed for a number of three floating bodies with different geometries consisting in an Anchor Handling Tug Supply (AHTS) vessel, a floating crane and a semisubmersible and three pipe laying vessels having different characteristics according to the location of operation. All data related to the main characteristics of the bodies are presented in Table 1.

Mention should be made that the method used for the evaluation of the behaviour of the floating bodies are based on the slender body theory except the semisubmersible case where a 3D method using the Green function theory and source distribution technique on the wetted surface of the body was used [10].

As a next step, the evaluation of the accelerations was carried out using a computer code based on the RAO's and the JONSWAP spectrum as inputs. The values of the accelerations, presented as fractions of the gravitational one, are calculated in a point placed on the starboard side of the midships section at the main deck level, according to the international requirements [9].

Table 1. Principal characteristic of the floating bodies

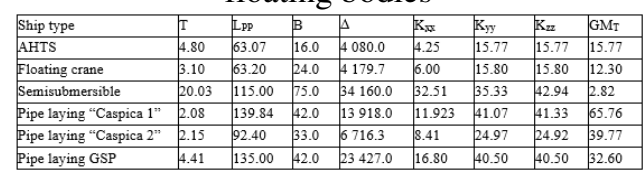

The significance of the notations in Table 1 is:

$\mathrm{L}_{\mathrm{PP}}$ - Length between perpendiculars $[\mathrm{m}]$;

B - Breadth [m];

$\mathrm{T}$ - Draught $[\mathrm{m}]$;

$\Delta$ - Displacement [t];

$\mathrm{K}_{\mathrm{xx}}-$ Roll radius of gyration [m];

$\mathrm{K}_{\mathrm{yy}}$ - Pitch radius of gyration [m];

$\mathrm{K}_{\mathrm{zz}}$ - Yaw radius of gyration [m];

$\mathrm{GM}_{\mathrm{T}}-$ Metacentric height [m].

\section{CALCULATION OF THE RESPONSE AMPLITUDE OPERATORS (RAO's)}

The evaluation of the RAO's, when the slender body theory is applicable, has been performed by using a computer code based on the well-known theory developed by Salvesen, Tuck and Faltinsen [8]. The program is using the "close fit source distribution technique", developed by Frank. Based on the calculation of the velocity potential (solving the classical boundary problem with initial conditions), the pressure distribution on the hull is obtained using Bernoulli's equation. Integrating the pressure on the wetted surface of the body the hydrodynamic diffraction forces and moments, induced by regular waves, are obtained. Then, together with the radiation forces and moments (expressed as added mass and damping coefficients), the evaluation of the amplitudes and phases for all six degrees of freedom, i.e. surge, sway, heave, roll, pitch and yaw motions become possible [1], [6]. The coordinate system is presented in Figure 1.

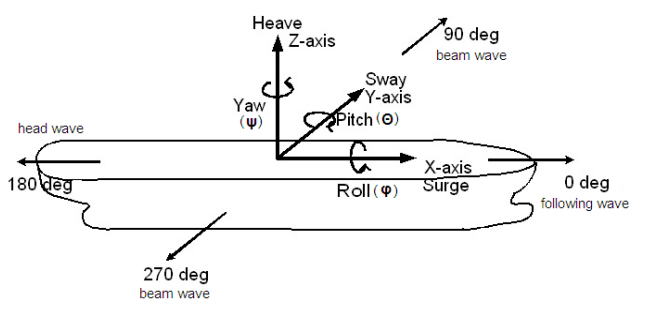

Fig.1. Motions and coordinate system

The calculations of the motions have been performed for a number of heading angles in the range $0^{\circ} \div 180^{\circ}$ with a step of $15^{\circ}$. Taking into account the double symmetry of five of the considered bodies the results are presented only for $0^{\circ}, 45^{\circ}$ and $90^{\circ}$ heading angles. In the case of the AHTS ship, some relatively small differences have been found. Consequently, in the present study, only the influences on the accelerations are reported for the entire range of heading angles $(\chi)$.

In order to be able to have a better perception of the influences of heading angle on the bodies' behaviour, the results are presented comparatively for each motion in the figures below, using the ship length and wave length nondimensional ratio . 


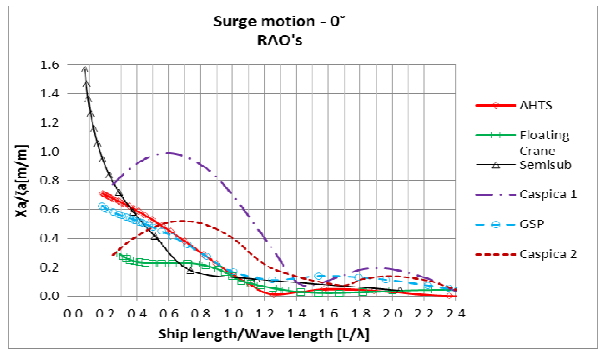

Fig.2. RAO's surge, $\chi=0^{\circ}$

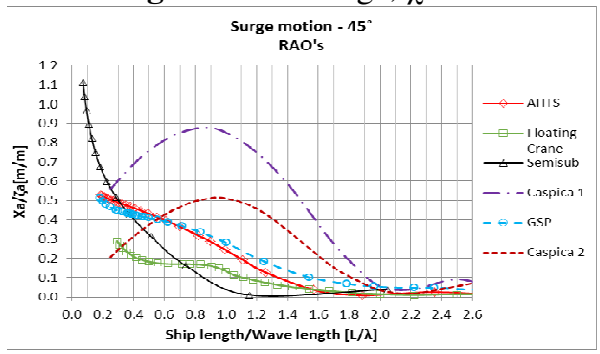

Fig.3. RAO's surge, $\chi=45^{\circ}$

Sway motion $-45^{\circ}$

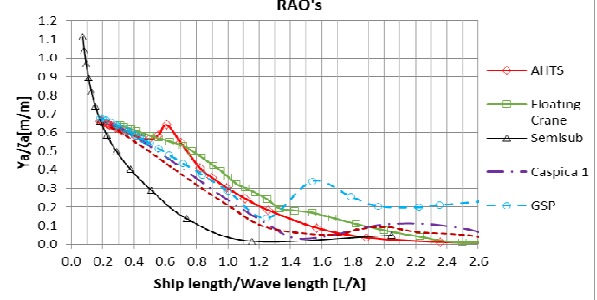

Fig.4. RAO's sway, $\chi=45^{\circ}$

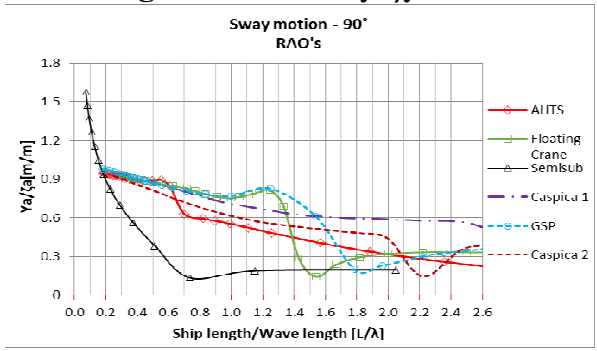

Fig.5. RAO's sway, $\chi=90^{\circ}$

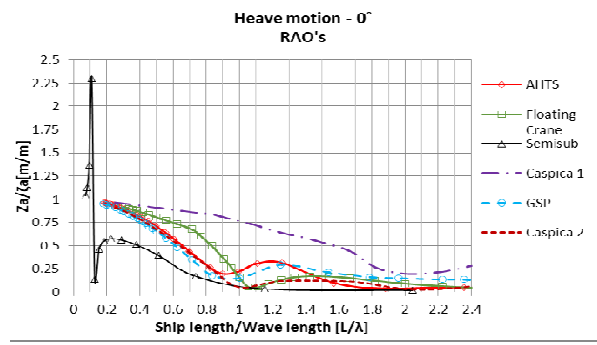

Fig.6. RAO's heave, $\chi=0^{\circ}$

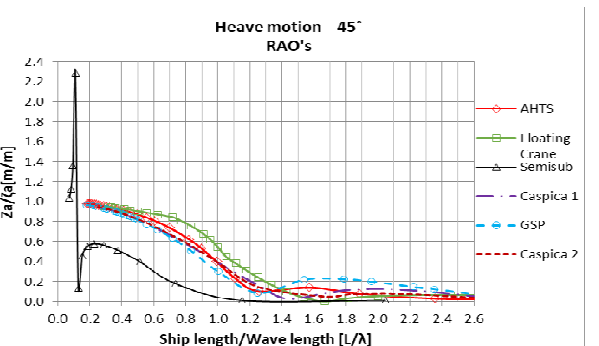

Fig.7. RAO's heave, $\chi=45^{\circ}$

Heave motion $\mathbf{9 0}^{-}$

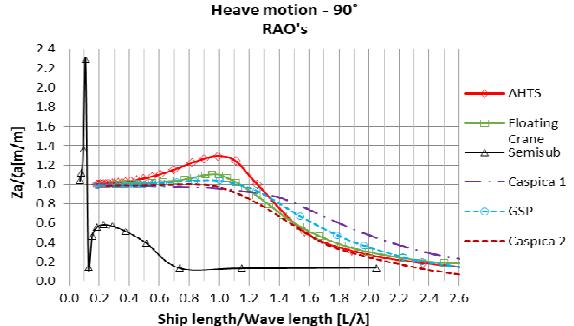

Fig.8. RAO's heave, $\chi=90^{\circ}$

Roll motion - 15

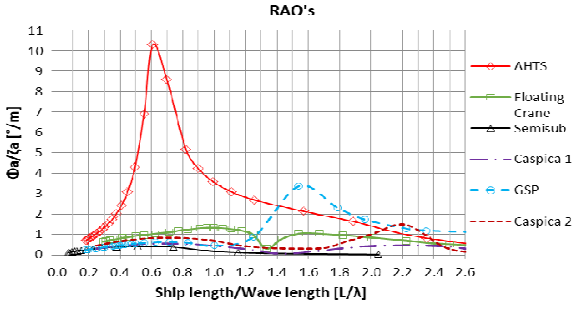

Fig.9. RAO's roll, $\chi=45^{\circ}$

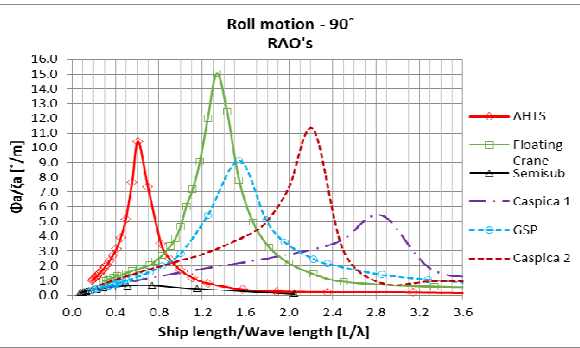

Fig.10. RAO's roll, $\chi=90^{\circ}$

Roll motion - $90^{\circ}$

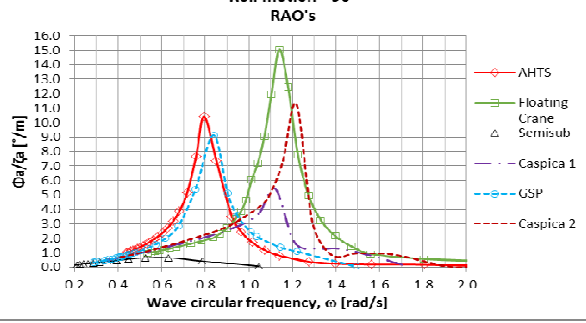

Fig.11. RAO's roll, $\chi=90^{\circ}$ 


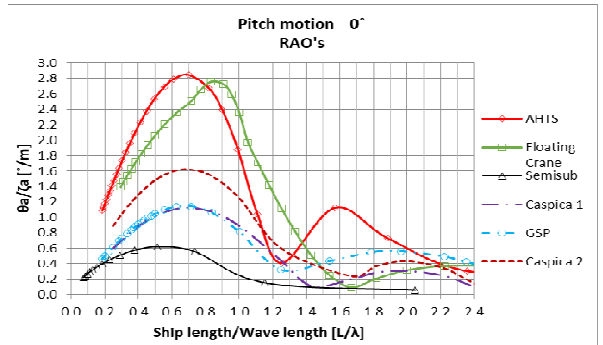

Fig.12. RAO's pitch, $\chi=0^{0}$

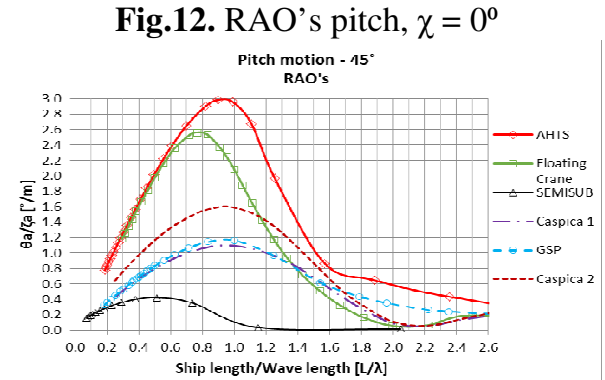

Fig.13. RAO's pitch, $\chi=45^{\circ}$

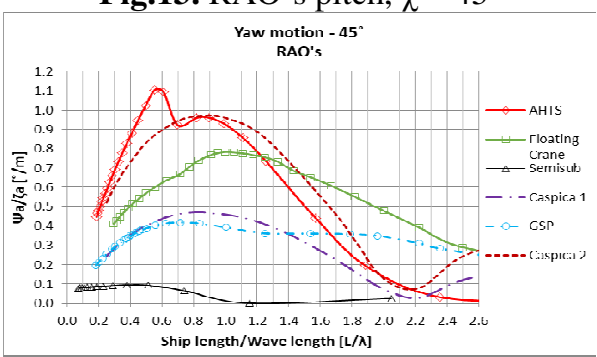

Fig.14. RAO's yaw, $\chi=45^{\circ}$

\section{DEFINITION OF THE SEA SPECTRUM}

In order to be able to calculate the accelerations, the JONSWAP sea spectrum was used for this particular application. Mention should be made that JONSWAP formulation is the most required one by the classification societies and the owners when not enough information is available for the location where the floating structures have to be placed. The general formulation of the above mentioned spectrum, given by Hasseman in 1973, is [7]:

$S(\omega)=\frac{\omega g^{2}}{\omega^{5}} \exp \left[-1.25\left(\frac{\omega}{\omega_{0}}\right)^{-4}\right] \gamma^{\operatorname{\omega g}\left[-\frac{\left(\omega-\omega_{0}\right)^{2}}{2 \sigma^{2} \omega_{0}^{2}}\right]}$ where: $\gamma$ - peakedness parameter, $1 \leq \gamma \leq 7$; $\omega$ - circular frequency;
$\alpha=0.076\left(\mathrm{X}_{0}\right)^{-0.22}, \alpha=0.0081$ when $\mathrm{X}$ is unknown.

The spectral density of the JONSWAP sea spectrum corresponding to Sea State 4 and Sea State 8 are presented in Figure 15 and Figure 16, respectively.

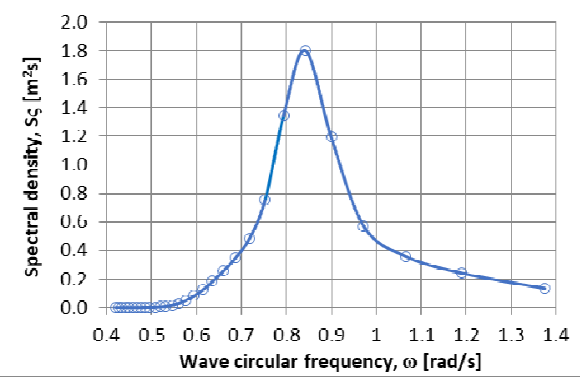

Fig.15. JONSWAP spectrum related to SS4

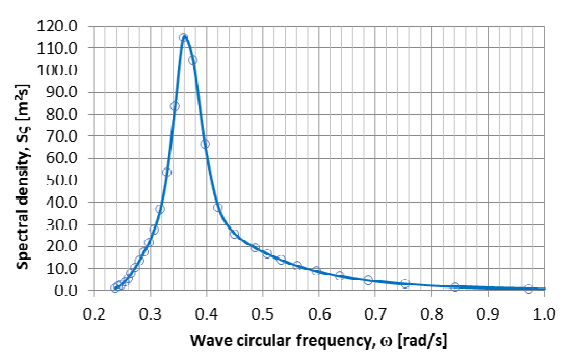

Fig.16. JONSWAP spectrum related to SS8

\section{CALCULATION OF ACCEL- ERATIONS}

As previously mentioned, the accelerations have been evaluated based on a computer code having as input data the already calculated RAO's and the spectral density for two Sea States (SS).

The calculations of the accelerations correspond to the points situated on the starboard of the amidships section at the main deck level. The locations correspond to the recommendations in order to evaluate if the results are complying with the norms related to human effectiveness on board [9]. The limits of the accepted values are presented in Table 2.

The positions of the locations where the accelerations have been calculated are presented in Table 3 for each ship. 
It is mandatory to carry out the evaluations in order to identify the limits of the sea states up to which the personnel is able to perform different kind of activities. In other words, these evaluations provide the necessary information in order to be able to define the operational indexes for a floating structure, depending on the type of operation to be performed in open sea.

Table 2. Seakeeping performance criteria for human effectiveness properties

\begin{tabular}{|c|c|c|c|}
\hline \multirow{2}{*}{ Description } & \multicolumn{3}{|c|}{ Root Mean Square Criterion } \\
\cline { 2 - 4 } & $\begin{array}{c}\text { Vert. Acc. } \\
\left(\mathrm{a}_{\mathrm{z}}\right)_{\mathrm{rms}} / \mathrm{g}\end{array}$ & $\begin{array}{c}\text { Lat. Acc. } \\
\left(\mathrm{a}_{\mathrm{y}}\right)_{\mathrm{rms}} / \mathrm{g}\end{array}$ & $\begin{array}{c}\text { Roll } \\
\text { Mot. } \\
\varphi_{\mathrm{rms}}\left[^{\circ}\right.\end{array}$ \\
\hline $\begin{array}{c}\text { Light Manual } \\
\text { Work }\end{array}$ & $0.20 \mathrm{~g}$ & $0.10 \mathrm{~g}$ & $6.0^{\circ}$ \\
\hline $\begin{array}{c}\text { Heavy Manual } \\
\text { Work }\end{array}$ & $0.15 \mathrm{~g}$ & $0.07 \mathrm{~g}$ & $4.0^{\circ}$ \\
\hline $\begin{array}{c}\text { Intellectual } \\
\text { Work }\end{array}$ & $0.10 \mathrm{~g}$ & $0.05 \mathrm{~g}$ & $3.0^{\circ}$ \\
\hline $\begin{array}{c}\text { Transit } \\
\text { Passengers }\end{array}$ & $0.05 \mathrm{~g}$ & $0.04 \mathrm{~g}$ & $2.5^{\circ}$ \\
\hline Cruise Liner & $0.02 \mathrm{~g}$ & $0.03 \mathrm{~g}$ & $2.0^{\circ}$ \\
\hline
\end{tabular}

Table 3. The positions of the locations related to the centre of gravity of each floating body

\begin{tabular}{|l|c|c|c|}
\hline \multirow{2}{*}{\begin{tabular}{c} 
Locations \\
\multirow{2}{*}{$\begin{array}{c}\text { accelerations } \\
\text { of the } \\
\text { evaluation }\end{array}$}
\end{tabular}} & \multicolumn{3}{|c|}{$\begin{array}{c}\text { Coordinates } \\
\text { of the evaluation point } \\
\text { related to the Center of } \\
\text { Gravity of each body [m] }\end{array}$} \\
\cline { 2 - 4 } & $\mathrm{X}_{\mathrm{i}}$ & $\mathrm{Y}_{\mathrm{i}}$ & $\mathrm{Z}_{\mathrm{i}}$ \\
\hline AHTS & 28.80 & 6.80 & 6.80 \\
\hline Floating Crane & 32.00 & 10.00 & 1.00 \\
\hline Semisubmersible & 55.50 & 30.00 & 16.00 \\
\hline Caspica 1 & 70.00 & 42.00 & 10.00 \\
\hline GSP & 62.00 & 21.00 & 10.00 \\
\hline Caspica 2 & 43.10 & 16.50 & 8.00 \\
\hline
\end{tabular}

Due to the fact that the AHTS ship has only bilateral symmetry, in Table 4 are presented the accelerations for the whole range of the defined heading angles [2]. The results can be effectively used to identify the heading angles to be avoided in order to reach acceptable values as compared to recommended ones (see Table 2).

Table 4. Root mean square (rms) values of the roll angles, lateral and vertical accelerations - the AHTS ship case.

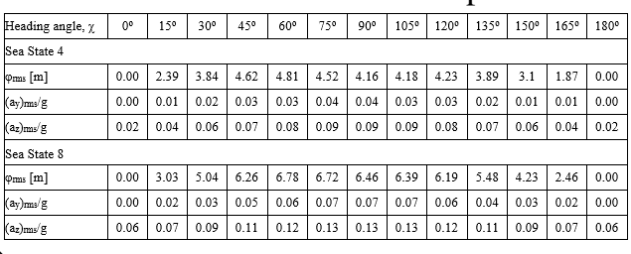

In Tables 5 and Table 6 can be found the results of the accelerations values for the other 5 floating bodies corresponding to the two Sea States considered for the evaluations.

Table 5. The results corresponding to Sea State 4 (for 5 floating bodies)

\begin{tabular}{|c|c|c|c|c|}
\hline \multicolumn{5}{|l|}{ Sea State 4} \\
\hline Heading angle & \multicolumn{3}{|l|}{$90^{\circ}$} & \multirow{2}{*}{\begin{tabular}{|l}
$180^{\circ}$ \\
$\left(a_{z}\right) m s / g$
\end{tabular}} \\
\hline Roll amplitudes and accelerations & $\varphi_{\operatorname{man}}\left[{ }^{[1]}\right.$ & $(\mathrm{ay})_{\mathrm{mm}} / \mathrm{g}$ & $\left(a_{2}\right)_{\operatorname{mos}} / \mathrm{g}$ & \\
\hline AHTS & 4.16 & 0.004 & 0.090 & 0.020 \\
\hline Floating Crane & 4.05 & 0.053 & 0.126 & 0.095 \\
\hline Semisubmersible & 0.30 & 0.007 & 0.010 & 0.007 \\
\hline Caspica 1 & 2.05 & 0.071 & 0.107 & 0.027 \\
\hline GSP & 5.48 & 0.100 & 0.179 & 0.047 \\
\hline Caspica 2 & 2.83 & 0.080 & 0.135 & 0.048 \\
\hline
\end{tabular}

Table 6. The results corresponding to Sea State 8 (for 5 floating bodies)

\begin{tabular}{|c|c|c|c|c|}
\hline \multicolumn{5}{|l|}{ Sea State 8} \\
\hline Heading angle & $90^{\circ}$ & & & $180^{\circ}$ \\
\hline Roll amplitudes and accelerations & $\varphi_{\operatorname{man}}[\mathrm{l}]$ & $(\mathrm{ay})_{\mathrm{m} m} / \mathrm{g}$ & $\left(a_{z}\right)_{\operatorname{man}} / \mathrm{g}$ & $\left(a_{z}\right) m s / g$ \\
\hline AHTS & 6.46 & 0.070 & 0.130 & 0.060 \\
\hline Floating Crane & 4.74 & 0.066 & 0.143 & 0.125 \\
\hline Semisubmersible & 2.05 & 0.052 & 0.047 & 0.056 \\
\hline Caspica 1 & 3.57 & 0.107 & 0.150 & 0.133 \\
\hline GSP & 5.84 & 0.123 & 0.191 & 0.134 \\
\hline Caspica 2 & 3.89 & 0.106 & 0.167 & 0.121 \\
\hline
\end{tabular}

\section{CONCLUSIONS}

Due to the fact that the accelerations are among the most important outputs of such an analysis, it is necessary to carry out calculations for a higher number of Sea States. Then, a thinner evaluation of the operational index can be obtained. The results of the applications performed for the analysed floating structures are for a limited number of heading 
angles considered to be the most dangerous cases.

If the metocean information regarding the statistics of the wave, current and wind on a given location is available, the problem of the above mentioned index is easier to be solved by identifying the possible operational time over the year.

An important observation is that except the low wave frequencies, the semisubmersible is the most suitable solution but, unfortunately, an expensive one. In this case roll motion has very low amplitudes over the full range of the investigated frequencies.

Mention should be made that, for a relatively short time of operation on a location, like the floating crane or AHTS cases, the root mean square (rms) values are enough to evaluate the dynamic behaviour in terms of comfort indexes. If a floating structure has to operate continuously on a given location, then the distribution of the significant wave height dependence on the cumulative probability has to be evaluated in order to have a basis to compare the values to be used for design purposes, using the design wave principle [5].

The results presented in the paper could be considered as a first attempt in creating a comparative overview on the behaviour of six floating bodies, having different geometries, mass distributions and natural frequencies covering some typical offshore activities [3]. An example is presented in Figure 11, where the spreading of natural frequencies when resonance could happen for each floating body can be observed.

As already mentioned, a dedicated application can be performed for a specific location when knowing the wave spectrum, combined with the evaluation of the wave induced forces and moments on ship girder.

\section{Acknowledgements}

The authors would like to express their gratitude and to thank GSP SA Constanța and NASDIS Consulting SRL Galați for the kindly offered support by putting at our disposal technical reports, valuable information and advice which made it possible for us to write the present paper.

\section{REFERENCES}

[1]. Bhattacharyya, R., "Dynamics of Marine Vehicles”, John Wiley \& Sons Publishing House, New York, USA, 1982

[2]. Crudu, L., "Seakeeping performances of an AHTS ship", The Annals of the University „Dunarea de Jos” of Galati, Fascicle XIShipbuilding, 2016

[3]. Crudu, L., Neculet, O., Mihalache, C., "Influences of mass distribution on seakeeping performances of an offshore barge", The Annals of the University „Dunarea de Jos” of Galati, Fascicle XIShipbuilding, 2016

[4]. Crudu, L., "Theoretical and Experimental Applications in Offshore Engineering", The University Foundation „Dunarea de Jos” Publishing House, Galati, Romania, 2015.

[5]. Crudu, L., "Design wave principle and hydrodynamic induced loads for a pipelayer operating in specific areas", The Annals of the University „Dunarea de Jos” of Galati, Fascicle XI-Shipbuilding, 2014

[6]. Faltinsen, O. M., "Sea Loads on Ship and Offshore Structures", Cambridge University Press, Cambridge, UK, 1983

[7]. Journee, J.M.J., Massie, W.W., "Offshore Hydromechanics", Delft University of Technology, Delft, Netherlands, 2001

[8]. Salvesen, N., Tuck, E. O., Faltinsen, O., "Ship motions and sea loads", Transactions of the Society of Naval Architects and Marine Engineers 78, 1970

[9]. ***NORDFORSK, "Assessment of Ship Performance in a Seaway", Hirtshals bogtryk/Offset A/S, Copenhagen, Denmark, 1987

[10]. Zienkiewicz, O. C., Bettess, P., Kelly, D.E., "Numerical Methods in Offshore Engineering", John Wiley \& Sons Publishing House, New York, USA, 1980

Paper received on November $28^{\text {th }}$, 2019 